khai báo y tế... (nhân viên làm việc ngoài trời) hay nhân viên xử lý mẫu, phân tích mẫu trong phòng thí nghiệm... (nhân viên làm việc trong phòng xét nghiệm).

- Sự tăng nhiệt độ bên trong quân áo chống dịch khi mặc so với nhiệt độ bên ngoài của quân áo chống dịch làm tăng thêm gánh nặng thể lực và gánh nặng nhiệt ở nhân viên y tế, cán bộ phòng chống dịch

\section{TÀI LIỆ THAM KHẢO}

1. Cotter J.D. and Taylor N.A.S. (2005). The distribution of cutaneous sudomotor and alliesthesial thermosensitivity in mildly heatstressed humans: an open-loop approach. J Physiol, 565(Pt 1), 335-345.

2. DuBois A.B., Harb Z.F., and Fox S.H. (1990). Thermal discomfort of respiratory protective devices. Am Ind Hyg Assoc J, 51(10), 550-554.

3. Laird I.S., Goldsmith R., Pack R.J. and Vitalis A.. (2002). The effect on heart rate and facial skin temperature of wearing respiratory protection at work. Ann Occup Hyg, 46(2), 143-148.

4.Parsons KC .(2010). Human thermal environments. 2nd edn. London, UK: Taylor \& Francis

\title{
TỔNG QUAN VÊ CÁC THANG ĐIỂM LÂM SÀNG TRONG CHẨN ĐOÁN VA QUÁ PHÁT Ở TRẺ EM
}

\section{TÓM TẮT}

VA quá phát là bênh lý thường gặp ở trẻ em ước tính khoảng $49,70 \%{ }^{1}$. Chẩn đoán VA quá phát ở trẻ em gặp nhiều khó khăn trong quá trình thăm khám do trẻ không hợp tác. Một số trường hợp phải gây mê để đánh giá tình trang VA và xác định phương án xử trí. Nhiều tác giả đã nghiên cứu các thang điểm lâm sàng đểđánh giá mức độ VA quá phát. Chúng tôi tiến hành nghiên cứu từ tháng 11 năm 2020 đến tháng 6 năm 2021 về tổng quan luận điểmcác tài liệu khoa hoc được xuất bản trên thế giới với mục tiêu: tổng hợp các thang điểm lâm sàng chẩn đoán VA quá phát hiên có và nhận xét kết quảcủa các thang điểm này. Kết quả đạt được: có 10 bài báo toàn văn về thang điểm lâm sàng chẩn đoán VA quá phát đạt tiêu chuẩn. Thang điểmKappa score với độ chính xác là 86,9\%. Các triệu chứng lâm sàng thường gặp nhất là: ngủ ngáy $8 / 10$; sau đó là thở miêng $7 / 10$; ngừng thở khi ngủ $6 / 10$; khó thở khi ngủ 3/10; giọng mũi kín 3/10; triệu chứng ban ngày $3 / 10$; viêm tai giữa tái diễn $2 / 10$; viêm mũi họng tái diên 2/10; chảy mũi thường xuyên 2/10. 7/10 bài báo có thang điểm chiamức độ VA quá phát; $3 / 10$ bài báo chấm điểm triệu chứng lâm sàng. 4 thang điểm có mối tương quan với $X Q$ sọ bên $p<0,05$, 3thang điểm tương quan với nội soi tai mũi họng $\mathrm{p}<0,05,3$ thang điểm đánh gía độ nhạy và đặc hiệu so với nôii soi mũi lần lượt là $22 \%-71 \%$ và $88 \%-100 \%$.

Tư khóa: tổng quan luận điểm, VA quá phát, điểm triệu chứng lâm sàng.

\section{SUMMARY}

\section{SCOPING REVIEW: CLINICAL SYMPTOMS}

\author{
${ }^{1}$ Bênhh viện đa khoa Đức Giang \\ 2Trường Đai hoc Y Hà Nôii \\ Chịu trách nhiệm chính: Nguyễn Thị Phương Loan \\ Email: phuongloan1192@gmail.com \\ Ngày nhận bài: 8.6.2021 \\ Ngày phản biên khoa hoc: 29.7.2021 \\ Ngày duyệt bài: 9.8.2021
}

\section{Nguyễn Thị Phương Loan', Phạm Thị Bích Đào²}

\section{SCORE FOR DIAGNOSIS ADENOID HYPERTROPHY IN CHILDREN}

Adenoid hypertrophy is a common disease in children and with an estimated rate of $49.70 \%$. Diagnosis of adenoid hypertrophy in children faces many difficulties during examination because they scared. In some cases, anesthesia is required to assess the grade of adenoid. Many authors have studied on clinical symptoms score to diagnose adenoid hypertrophy. We conducted a scoping review from researchs in the world until 06/2021 with objectives synthesize the clinical symptoms scores is available and comment on the result of studies. The result show that 15 studies were selected. The common clinical symptoms are: snoring $8 / 10$; mouth breathing $7 / 10$; sleep apnea $6 / 10$; difficulty breathing while sleeping $3 / 10$; hyponasality $3 / 10$; daytime symptoms $3 / 10$; recurrent otitis media $2 / 10$; recurrent nasopharyngitis 2/10; discharge nose 2/10. 5/7 studies had a statistically significant correlation with lateral skull X-ray, 3 studies had a high correlation with nasal enoscopy, 3 studies assessed the sensitivity and specificity as $22 \%-78 \%$ and $88 \%-100 \%$. score.

Keywords: adenoid hypertrophy, clinical symptom

\section{I. ĐĂT VẤN ĐỀ}

VA quá phát là một trong những nguyên nhân chính gây viêm nhiễm tái diễn ở trẻ em trên mức độ cộng đồng và gây nhiều biến chứng toàn thân ảnh hưởng lâu dài tới cả thể chất và tinh thần trẻ. Chẩn đoán VA qúa phát hiện nay sử dụng 3 phương pháp chính là nội soimũi, XQ sọ bên vàđánh giá lâm sàng. Nội soi mũi được coi là tiêu chuẩn vàng tuy nhiên các bác sĩ thường gặp khó khăn do trẻ không hợp tác khi thăm khám. Nghiên cứu của tác giả Torretta² trên 900 bác sĩ tai mũi họng tại Ý cho thấy $64 \%$ phải sử dụng các biện pháp để kiềm chế trẻ, $22 \%$ bác sĩ 
cầngây mê để thực hiện nội soi. XQ sọ bên lại mang đến nguy cơ nhiếm tia xa cho trẻ và thường không có sẵn. Do đó, nhiều tác giả đã nghiên cứu các thang điểm lâm sàng chẩn đoán VA quá phát là phương pháp không xâm lấn, dễ dàng áp dụng ở trẻ em. Chính vì vậy, với mong muốn giúp cho bác sĩ lâm sàng có thêm cách nhìn đa chiều về các phương pháp chẩn đoán VA quá phát,chúng tôi thực hiện nghiên cứu này với mục tiêu: Tông hợp các thang điểm lâm sàng hiện có để chẩn đoán VA quá phát và nhận xét kêt quả các thang điểm này.

\section{II. ĐỐI TƯợNG VÀ PHƯƠNG PHÁP NGHIÊN CỨU}

\subsection{Tiểu chuẩn lựa chọn và loại trừ}

Tiêu chuẩn lựa chọn: Các nghiên cứu về chẩn đoán VA quá phát có chấm điểm triệu chứng lâm sàng, đánh giá kết quả bằng nội soi mũivà hoặc $X Q$ sọ bên. Các nghiên cứu ở trẻ em. Các nghiển cứu được xuất bản bằng tiếng Anh, tiếng Việt và đọc được toàn văn.Tiêu chuẩn loại trừ là những nghiên cứu ở trẻ Amydal lớn hơn độ II, có nguyên nhân gây ngạt mũi khác, nghiên cứu không đọc được toàn văn.

2.2. Nguồn cớ sở dữ liệu. Chúng tôi thực hiện tìm kiếm từ tháng 11/2020 đến tháng 6/2021 như sau:

- Thư Viện Đại Học Y Hà Nội với từ khóa:"VA quá phát" AND"chẩn đoán lâm sàng".

- Trên cơ sở dữ liệu y học trực tuyến Pudmed và Cohrane với từ khóa tìm kiếm: "Adenoid hypertrophy" AND "clinical diagnosis" OR "clinical score"

2.2.3 Quản lý và lựa chọn dữ liệu và trích xuất dữ liệu. Các nghiên cứu tìm được được đọc tiêu đề và tóm tắt theo tiêu chí lựa chọn tìm ra nghiên cứu toàn vănđể chọn các nghiên cứu phù hợp: tên tác giả, năm xuất bản, địa điểm, tên nghiên cứu, đối tượng nghiên cứu, tuổi, giới, triệu chứng lâm sàng, kết quả.
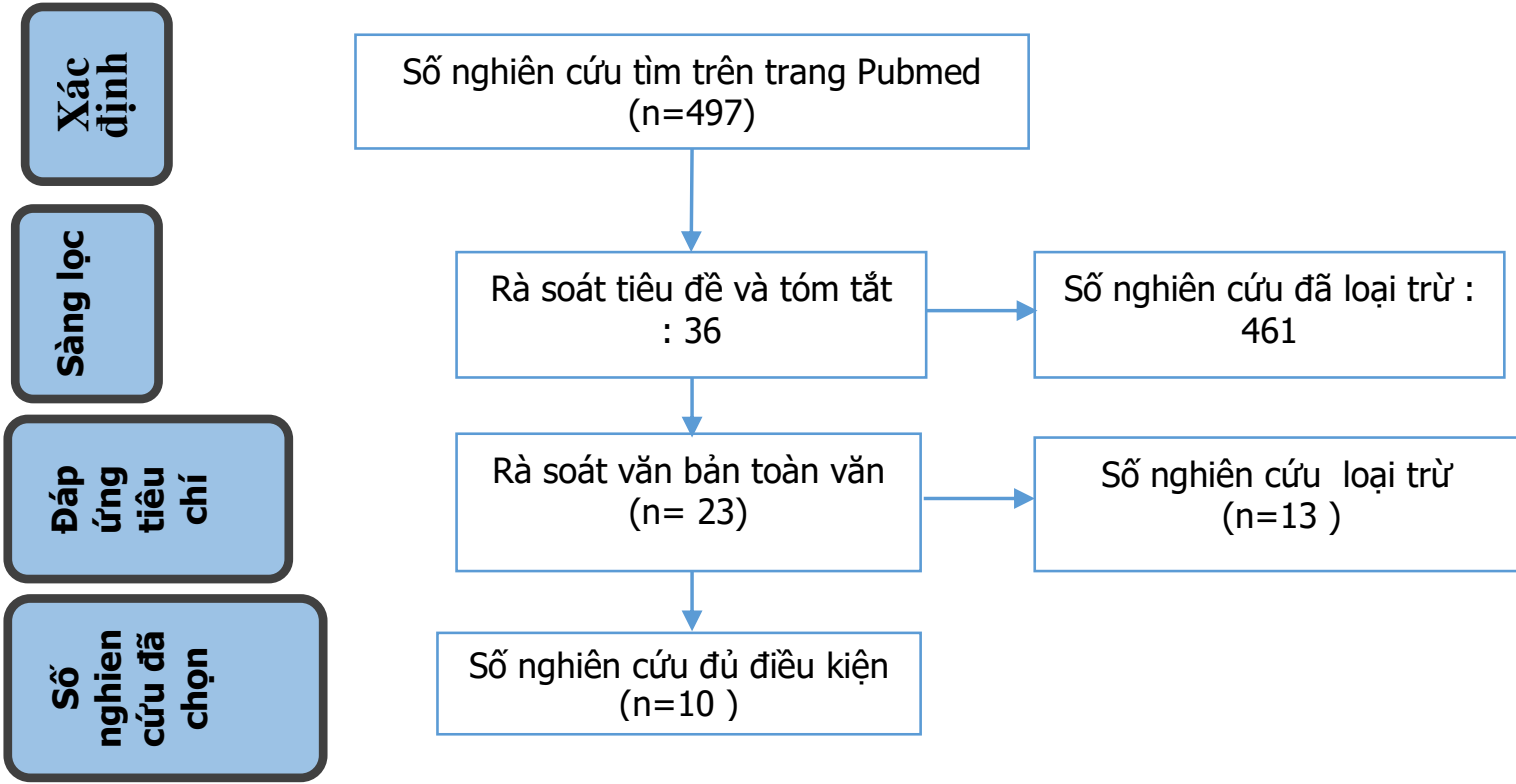

Hình 2.1 Sơ đồ chi tiết quá trình lựa chọn và loại trư các bài báo vào nghiên cứu.

\section{KẾT QUẢ NGHIÊN CứU}

3.1 Đặc điểm các bài báo trong nghiên cứu. Qua tìm kiếm trực tuyến trên hệ thống cơ sở dữ liệu của Pubmed, cohrane và Thư viện Trường đại học Y Hà Nội chúng tôi thu được 497 bài báo đưa vào nghiên cứu, sàng lọc - loại trừ đã thu được 10 bài báo trên 1775 bệnh nhân đáp ứng đử tiêu chí. Các nghiên cứu được công bố từ năm 1982- 2019. Bao gồm: 8/10 nghiên cứu tiến cứu, 2/10 nghiên cứu cắt ngang. Trong đó có $3 / 10$ nghiên cứu đánh giá giá trị của thang điểm triệu chứng lâm sàng, $7 / 10$ nghiên cứu xác định mối tương quan so với các phương pháp chẩn đoán khác.

\section{2. Đặc điểm của bệnh nhân trong} nghiên cứu

Về tuổi: Tuổi trung bình của các bệnh nhân trong nghiên cứu là từ 3 tuổi đến 11,8 tuổi; nhóm tuổi thường gặp nhất là khoảng 1 tuổi đến 5 tuổi. 3/10 nghiên cứu có mối tương quan giữa tuổi và mức độ VA quá phát.

Về giới: Tỉ lệ nam giới trong các nghiên cứu thu được từ $53,3 \%$ đến $65,6 \%$.

3.3 Đặc điểm của các thang điểm lâm 
sàng. Triệu chứng thường gặp nhất trong các nghiên cứu là: ngủ ngáy $8 / 10$; sau đó là thở miệng $7 / 10$; ngừng thở khi ngủ $6 / 10$; khó thở khi ngủ 3/10; âm mũi kín $3 / 10$; triệu chứng ban ngày $3 / 10$; viêm tai giữa tái diễn $2 / 10$; viêm mũi họng tái diễn $2 / 10$; chảy mũi thường xuyên $2 / 10$.
Ngủ ngáy là triệu chứng có tương quan tốt nhất với mức độ hẹp đường thở trên XQ. 7 nghiên cứu đánh giá mức độ quá phát VA.3 nghiên cứu chỉ chấm điểm triệu chứng lâm sàng. Các thang điểm triệu chứng lâm sàng được mô tả cụ thể trong bảng dưới đây.

Bảng 3.1 Các thang điểm lâm sàng chẩn đoán VA quá phát.

\begin{tabular}{|c|c|c|}
\hline Tên tác giả/ & Các triệu chứnglâm sàng & Thang điểm \\
\hline Crepeau 1982 & $\begin{array}{l}\text { Nhóm } 3 \text { triệu chứng chính: thở miệng, } \\
\text { ngáy, ngạt mũi mãn tính } \\
\text { Nhóm } 3 \text { triệu chứng phụ: viêm đường hô } \\
\text { hấp trên tái diên, viêm tai giữa tái diê̂n, } \\
\text { nói giọng mũi kín }\end{array}$ & $\begin{array}{l}1 \text { điểm: không triệu chứng } \\
2 \text { điểm: không triệu chứng chính, } \geq 1 \\
\text { triêeu chứng phụ; } 3 \text { điểm: } 1 \text { triệu chứng } \\
\text { chính (có hoặc không triếu chứng phụ) } \\
4 \text { điểm: } 2 \text { triệu chứng chính } \\
5 \text { điểm: } 3 \text { triệu chứng chính }\end{array}$ \\
\hline Bitar 2006 & $\begin{array}{c}5 \text { triệu chứng: thở miệng, ngủngáy, ngủ } \\
\text { trằn trọc, thường xuyên tỉnh giấc đêm, } \\
\text { ngừng thở khi ngủ. }\end{array}$ & $\begin{array}{c}\text { Mối triệu chứng } 1 \text { điểm, tổng } 5 \text { điểm. } \\
\text { Điểm triệu chứng > } 3 \text { gợi ý VA quá phát } \\
\text { che lấp đường thở vữa đến nặng }\end{array}$ \\
\hline ORji 2008 & $\begin{array}{l}3 \text { triệu chứng: ngáy, thở miệng, ngừng thơ } \\
\text { khi ngủ. } \\
\text { Chấm điểm: không có: } 0 \text { điểm, nhe } 1 \\
\text { điểm, trung bình } 2 \text { điểm, nặng } 3 \text { điểm. }\end{array}$ & $\begin{array}{c}\text { tống 1-9 điểm, chia thành } 3 \text { mức độ } \\
\text { Nhe: } 1-3 \text { điểm } \\
\text { Vừa: } 4-6 \text { điểm } \\
\text { Nặng: } 6-9 \text { điểm }\end{array}$ \\
\hline Taiwo 2016 & $\begin{array}{l}6 \text { triệu chứng: ngạt mũi, thở ôn ào, Thở } \\
\text { miệng, ngáy, chảy nước mũi, buô̂n ngủ } \\
\text { vào ban ngày, Kém phát triển. }\end{array}$ & $\begin{array}{c}\text { Tống điểm 13, chia } 3 \text { mức đồ } \\
\text { <6 gợi ý tắc nghẽn đường thở nhẹ } \\
\text { 6-9 tắc nghên đường thở vừa } \\
>9 \text { tắc nghẽn đường thở nghiêm trọng }\end{array}$ \\
\hline $\begin{array}{c}\text { Paradise } \\
1998\end{array}$ & $\begin{array}{c}\text { Chỉ số tắc nghẽn mũi NOI gồm: } \\
\text { thở miệng, giọng mũi kín. } \\
\text { Đánh giá ở } 4 \text { mức độ: bình thường, nhẹ, } \\
\text { vữa, năng. }\end{array}$ & $\begin{array}{l}\text { Kết quả là: } \\
1 \text { điểm: bình thường } \\
2.5 \text { điểm: VA quá phát nhe } \\
4 \text { điểm: quá phát năng }\end{array}$ \\
\hline Torreta 2011 & NOI & Như trên \\
\hline Wormald 1992 & $\begin{array}{c}6 \text { triệu chứng: thở miệng khi thức, thở ôn } \\
\text { ào khi thức, thở miêng khi ngủ, ngáy khi } \\
\text { ngủ, ngủ không yên giấc hoặc khó thở khi } \\
\text { ngư, ngưng thở khi ngủ. }\end{array}$ & $\begin{array}{l}\text { Mỗi triệu chứng } 1 \text { điểm, } \\
\text { tổng là } 6 \text { điểm. }\end{array}$ \\
\hline $\begin{array}{l}\text { Shervin } \\
\text { sharifkashani } \\
2015\end{array}$ & $\begin{array}{c}3 \text { triệu chứng: khó thở khi ngủ } D \text {, Ngưng } \\
\text { thở khi ngủ } A, N g a ́ y ~ \\
\text { Điểm của bệnh nhân }=1,42 D+1,41 A \\
+0,71 S-3,83\end{array}$ & $\begin{array}{c}\text { Chia làm } 3 \text { mức độ VA quá phát : } \\
\text { Nhẹ: } \leq-1 \text { điểm } \\
\text { Vừa: }-1 \text { đến } 3,5 \text { điểm } \\
\text { Nặng: }>3,5 \text { điểm }\end{array}$ \\
\hline $\begin{array}{l}\text { Moideen } \\
2019\end{array}$ & 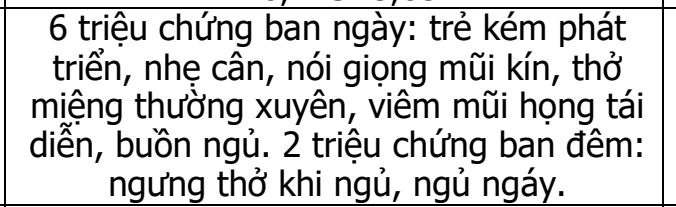 & $\begin{array}{c}\text { Tống điểm 0-10. Chia làm } 4 \text { mức độ: } \\
\text { độ } 1 \text { ( } 0 \text { đến } 2 \text { điểm): nhè. } \\
\text { độ } 2 \text { (3 đến } 5 \text { điểm): trung bình } \\
\text { độ } 3 \text { (6-7 điểm): trung bình đến nặng } \\
\text { độ } 4 \text { (8-10 điểm): nặng. }\end{array}$ \\
\hline $\begin{array}{l}\text { Kugelman } \\
2019\end{array}$ & $\begin{array}{l}5 \text { triệu chứng: ngáy, gionng mũi kín, số lần } \\
\text { dừng thở hoắc tỉnh giấc đêem, số ngày chảy } \\
\text { mũi trong tuần, tần suất viêm tai giữa. }\end{array}$ & $\begin{array}{c}\text { Các triệu chứng được chấm từ 1-4 điểm, } \\
\text { tổng điểm là 5-20 điểm. }\end{array}$ \\
\hline
\end{tabular}

3.4. Kết quả nghiên cứu các thang điểm lâm sàng. Đánh giá kết quả của thang điểm dựa trên so sánh với các phương pháp chẩn đoán khác, cụ thể là 4 nghiên cứu so sánh với XQ so bên, 3 nghiên cứu so sánh với nội soi tai mũi họng, 3 nghiên cứu so sánh với cả $X Q$ sọ bên và nội soi tai mũi họng.

Bốn nghiên cứu có mối tương quan với XQ sọ bên như sau. Hai nghiên cứu củaBitar vàTaiwo đều thu được điểm triệu chứng tương quan với mức độ tắc nghẽn đường thở trên chụp $X Q$ sọ bên $p<0,05$. Nghiên cứu của Crepeau cho rằng 
có mối tương quan nghịch giữa kích thước $A A$ trên phim XQ sọ bên và số lượng triệu chứng, hay đường thở càng hẹp điểm triệu chứng càng cao $p<0,001$. Nghiên cứu ORji điểm triệu chứng tương quan đáng kể với mức độ tắc nghẽn đường thở trên xq cổ bên $r=0,419, p<0,001$.

Ba nghiên cứu đánh giá giá trị của thang điểm so với nội soi mũi kết quả như sau: Toretta và cộng sự nghiên cứu trên số lượng bệnh nhân nhiều nhất là 1033 cho thấy độ nhạy và độ đặc hiệu của NOI tùy thuộc vào ngưỡng lần lượt là $22 \%, 88 \%$; UAC là 0,7\% ở tất cả các ngướng. Paradise và cộng sự cho kết quả độ nhạy $78 \%$ khi điểm NOI đạt mức thấp nhất là 1,5 và độ đặc hiệu 93-100\% khi NOI đạt 2,5- 4 điểm. Độ nhạy và độ đặc hiệu nhiều biến nên thay đổi ngược chiều nhau. Woldman cho thấy độ nhạy $96 \%$ và độ đặc hiệu $90 \%$, PVC $92 \%$ và NVC $90 \%$.

Ba nghiên cứu đánh giá kết quả bởi cả $X Q$ và nội soi mũi như sau. Moideen điểm triệu chứng tương quan với $X Q$ sọ bên $p<0,05$ và cả nội soi $p<0,001$. Shervin sharaki thang điểm tương quan với nội soi $p<0,001$ không tương quan với $X Q p>0,05$. Nirkugelman điểm triệu chứng có mối tương quan với nội soi mũi $r=0,462 p<0,05$ nhưng không tương quan với XQ r=-0,05, p>0,05.

Bảng 3.2 Kêt quả các thang điểm lâm sàng chẩn đoán VA quá phát

\begin{tabular}{|c|c|c|c|c|c|c|c|c|}
\hline $\begin{array}{c}\text { Tên tác giả } \\
\text { Jăm } \\
\text { nấ } \\
\text { nghiên cứu }\end{array}$ & $\begin{array}{l}\text { Quốc } \\
\text { gia }\end{array}$ & $\begin{array}{l}\text { Thiết kế } \\
\text { nghiên } \\
\text { cứu }\end{array}$ & $\begin{array}{c}\text { Tuối trung } \\
\text { bình/ } \\
\text { Tỷ lệ giới } \\
\text { nám }\end{array}$ & $\begin{array}{c}\text { Cõ̃ } \\
\text { mâ̂́u } \\
\text { N }\end{array}$ & $\begin{array}{c}\text { Phương } \\
\text { pháp đánh } \\
\text { giá kết quả }\end{array}$ & $\begin{array}{l}\text { Kết quả về } \\
\text { mối tương } \\
\text { quan }\end{array}$ & $\begin{array}{c}\text { Độ nhạy } \\
\text { /độ̣ } \\
\text { đạc } \\
\text { hiêu \%o }\end{array}$ & $\begin{array}{l}\text { NPV/ } \\
\text { PPV \% }\end{array}$ \\
\hline $\begin{array}{c}\text { Crepeau } \\
1982\end{array}$ & Canada & Cắt ngang & $\begin{array}{l}\text { None } \\
\text { None }\end{array}$ & 100 & $-X Q$ AA & $\begin{array}{l}r=0,39 ; \\
p<0,001\end{array}$ & & \\
\hline Bitar 2006 & Lebanon & Tiến cứu & $\begin{array}{l}4,25 \\
59,3\end{array}$ & 154 & $\begin{array}{c}\text {-XQ cohen } \\
\text { konak } \\
\text {-Gương glazel }\end{array}$ & $\begin{array}{l}p<0,05 \\
p<0,001\end{array}$ & & \\
\hline ORji 2008 & Nigieria & Tiến cứu & $\begin{array}{l}\text { None } \\
65,6\end{array}$ & 64 & XQ A/N & $\begin{array}{c}r=0,419 \\
p<0,001 .\end{array}$ & & \\
\hline Taiwo 2016 & Nigieria & Cắt ngang & $\begin{array}{c}3,0 \pm 2,3 \\
67,8\end{array}$ & 90 & $\mathrm{XQ} A / N$ & $p<0,05$ & & \\
\hline $\begin{array}{c}\text { Paradise } \\
1998 \\
\end{array}$ & Mỹ & Tiến cứu & None & 86 & Nội soi mũi & & $\begin{array}{c}78 / \\
90-100\end{array}$ & \begin{tabular}{|c|}
$86-100 /$ \\
$80-86$
\end{tabular} \\
\hline $\begin{array}{c}\text { Torretta } \\
2011\end{array}$ & Italy & Cắt ngang & $\begin{array}{r}5,4 \\
53,3 \\
\end{array}$ & 1033 & Nội soi mũi & & $22-88$ & \\
\hline $\begin{array}{c}\text { Wormald } \\
1992\end{array}$ & Nam Phi & Tiến cứu & $\begin{array}{l}4,71 \\
60,8\end{array}$ & 74 & Nội soi mũi & $\begin{array}{l}r=0,85 \\
p<0,001\end{array}$ & $96 / 90$ & $92 / 90$ \\
\hline \begin{tabular}{|c|} 
Shervin \\
sharifkashan \\
i 2015 \\
\end{tabular} & Iran & Tiến cứu & $\begin{array}{c}11,8 \pm 2,79 \\
56,6\end{array}$ & 90 & $\begin{array}{l}\text {-XQ cohen } \\
\text { konak } \\
\text {-Nội soi mũi }\end{array}$ & $\begin{array}{c}p>0,05 \\
p<0,001\end{array}$ & & \\
\hline $\begin{array}{l}\text { Moideen } \\
2019\end{array}$ & Ấn độ & Tiến cứu & $\begin{array}{l}\text { None } \\
54,1\end{array}$ & 48 & $\begin{array}{c}\dot{X Q} A / N \\
\text {-nội soi mũi }\end{array}$ & $\begin{array}{l}p<0,005 \\
p<0,001\end{array}$ & & \\
\hline $\begin{array}{l}\text { Kugelman } \\
2019\end{array}$ & Israel & Tiến cứu & $\begin{array}{l}5,33 \\
58,3\end{array}$ & 36 & $\begin{array}{c}\text {-XQ A/N } \\
\text {-Nội soi mũi }\end{array}$ & $\begin{array}{c}r=-0,05 \\
p>0,05 \\
R=0,462 ; \\
P=0,05\end{array}$ & & \\
\hline
\end{tabular}

\section{BÀN LUẬN}

4.1. Đặc điểm về đối tượng trong nghiên cứu. Tiêu chuẩn lựa chọn của các nghiên cứu rõ ràng tuy nhiênchỉ 4 bài báo loại trừ các nguyên nhân khác gây tắc nghẽn mũi và 2 bài báo loại trừ amidan quá phát từ độ 3 nên có thể dẫn đển các sai lệch về kết quả. Độ tuổi thường gặp trong nghiên cứu là trẻ 1-5 tuổi, tương ứng kết quả của Pagella từ 1-7 tuổi đặc biệt ở VA độ IIIIV ${ }^{3}$. Điều nàyphù hợp với sự phát triển VA ở trẻ em từ 7 tháng đến 6 tuổi, sau đó 6-7 tuổi thoái triển dần. Tỉ lệ nam giới chiếm 53-65\% tỉ lệ giới tính của chúng tôi cũng phù hợp với nghiên cứu của Prestes L $2009^{4}$ nam giới chiếm 60,78\%.

4.2. Các thang điểm lâm sang. Các triệu chứng thường gặp nhất là thở miệng, ngủ ngáy và ngừng thở khi ngủ tương ứng với thang điểm của tác giả ORji 2008, kết quả này cũng phù hợp với nghiên cứu của Kingderman ${ }^{5}$ từng triệu chứng trên có mối tương quan với nội soi $p<0,001.7$ nghiên cứu có thang điểm lâm sàng chia độ quá phát VA nhẹ, vừa, nặng. chúng tôi cho rằng các thang điểm này đều có thể áp dụng trên thực hành lâm sàng. 
4.3. Kết quả các thang điểm. Theo kết quả nghiên cứu, các thang điểm lâm sàng đều có mối tương quan ý nghĩa với $X Q$ sọ bên và hoặc nội soi mũi, tuy nhiên độ chính xác của các thang điểm lâm sàng không được chứng minh rõ ràng do sự đa dạng của các phương pháp đánh giá, cõ mẫu khác nhau, các biến triệu chứng thay đổi. Trong đó, hai bài báo sử dụng thang điểm NOI có nhược điểm là chỉ đánh giá triệu chứng ban ngày mà bỏ qua triệu chứng ban đểm rất có ý nghĩa ở trẻ. Bên cạnh đó, chúng tôi nhận định rằng VA quá phát là một bệnh ít rủi ro cấp tính và nội soi chẩn đoán thường có sẵn nên độ nhạy thấp 22-78\% chấp nhận được bởi cùng với đó độ âm tính giả cao hơn; độ đặc hiệu cao $>88 \%$ cho thấy độ tin cậy của thang điểm, vì vậy có thể sử dụng thang điểm lâm sàng như 1 test sàng lọc bệnh.

Khi so sánh các nghiên cứu được lựa chọn, có một số hạn chế còn tồn tại. Đầu tiên, các nghiên cứu đã sử dụng 2 phương pháp đánh giá kết quả, kể cả khi sử dụng tiêu chuẩn vàng là nội soi tai mũi họng nhưng quy trình cũng không được chuẩn hóa. Thứ hai, chỉ có $3 / 10$ nghiên cứu đánh giá giá trị của các thang điểm lâm sàng. Cuối cùng, vì thiết kế nghiên cứu là tổng quan luận điểm, nên chúng tôi không đánh giá chất lượng của các bài báo đâu vào. Mặc dù vậy, các thang điểm lâm sàng đều đơn giản, cách chấm điểm kết quả rõ ràng nên dễ dàng áp dụng ở tuyến y tế cơ sở nhằm chẩn đoán sàng lọc bệnh trong cộng đồng và chỉ định phẫu thuật cho VA độ III, IV.

\section{KẾT LUẬN}

Các thang điểm lâm sàng trong nghiên cứu cho thấy 3 triệu chứng thường gặp nhất là thở miệng, ngủ ngáy, ngừng thở khi ngủ. Thang điểm lâm sàng có mối tương quan với nội soi mũi hơn Xq so bên, nhất là ở trẻ VA quá phát độ III, IV. Có thể áp dụng các thang điểm lâm sàng để chẩn đoán sàng lọc VA quá phát độ III, IV trong cộng đồng.

\section{TÀI LIÊU THAM KHẢO}

1. Pereira L, Monyror J, Almeida FT, et al. Prevalence of adenoid hypertrophy: A systematic review and meta-analysis. Sleep Med Rev. 2018;38:101-112. doi:10.1016/j.smrv.2017.06.001

2. Torretta S, Marchisio P, Succo G, Capaccio P, Pignataro L. Nasopharyngeal fiberendoscopy in children: a survey of current Italian pediatric otolaryngological practices. Ital J Pediatr. 2016;42:24. doi:10.1186/s13052-016-0234-y

3. Pagella $F$, De Amici $M$, Pusateri $A$, et al. Adenoids and clinical symptoms: Epidemiology of a cohort of 795 pediatric patients. Int J Pediatr Otorhinolaryngol. $\quad 2015 ; 79 \quad$ (12):2137-2141. doi:10.1016/ j.ijporl.2015.09.035

4. Prestes L, Neto G, Camera $M$. Adenotonsillectomy effect on the life quality of children with adenotonsillar hyperplasia. Int Arch Otorhinolaryngol. 2009;13.

5. Kindermann CA, Roithmann $R$, Lubianca Neto JF. Sensitivity and specificity of nasal flexible fiberoptic endoscopy in the diagnosis of adenoid hypertrophy in children. Int J Pediatr Otorhinolaryngol. 2008;72(1):63-67. doi:10.1016/ j.ijporl.2007.09.013

\title{
U KÝ SINH TRÙNG (SÁN DÂY LỢN) TRONG CƠ THẤT PHẢI - NHÂN MộT TRƯỜNG Hợ'P ĐIỀU TRI THÀNH CÔNG VÀ NHÌN LẠI Y VĂN
}

\author{
Phạm Hữu Lư ${ }^{1,2}$, Hoàng Trọng Hải ${ }^{2}$, Dương Hoàng Long ${ }^{2}$, \\ Phan Thùy Chi ${ }^{1,2}$, Nguyễn Tùng $S_{0} n^{2}$, Nguyễn $S \tilde{y} L^{2}{ }^{2} h^{2}$, \\ Phạm Hữu Khuyên ${ }^{2}$, Phùng Duy Hồng Sơn'², Khổng Tiển Bình'2, \\ Phạm Tiến Quân ${ }^{2}$, Nguyễn Hữu Ước ${ }^{1,2}$ \\ hoăc màng tim. Trong y văn có một số bài báo mô tả \\ thương tổn ở tim do kí sinh trùng nhưng chỉ dừng lại ở \\ những thông báo lâm sàng nhiễm ký sinh trong trong \\ đó có bênh tim do sán dây lợn. Tại bênh viện hữu \\ nghị Việt Đức: Chúng tôi thônng báo trường hợp lâm \\ sàng hiếm gặp về bệnh nhiễm sán dây lợn trong cơ \\ thất phải đã được chẩn đoán và xử trí. Phương pháp \\ nghiên cứu: Mô tả ca lâm sàng về triệu chứng lâm \\ sàng, cận lâm sàng và thái độ xử trí cho loại tổn \\ thương này. Trường hợp lâm sàng: Bênh nhân nữ 51 \\ tuổi, vào viện do khám sức khỏe định kỳ phát hiện \\ khối u vách liên thất trong buồng tâm thất phải, bệnh \\ nhân được chẩn đoán u cơ tim và có chỉ định sinh \\ thiết nhưng trong quá trình sinh thiết có biến chứng \\ thủng thành cơ tim, bệnh nhân được chỉ định phẫu
}

\section{TÓM TẮT}

Mở đâu: Bệnh kí sinh trùng là một bênh thường gặp ở các nước nhiệt đới. Bệnh này có thể có gây tổn thương ở nhiều cơ quan trong cơ thể trong đó có biểu hiên ở tim. Tim là cơ quan có thể bi ảnh hưởng trực tiểp hoặc gián tiếp, bệnh có thể biểu hiện ở cơ tim

${ }^{1}$ Đại học Y Hà Nọi

${ }^{2}$ Bềnh viên Hữu nghi Viêtt Đức

Chịu trách nhiệm chính: Phạm Hữu Lư

Email: phamhuulu@hmu.edu.vn

Ngày nhân bài: 7.6.2021

Ngày phản biên khoa hoc: 31.7.2021

Ngày duyệt bài: 9.8.2021 